\title{
Lead Titanate-Based Nanocomposite: Fabrication, Characterization and Application and Energy Conversion Evaluation
}

\author{
Walter Katsumi Sakamotoํㅜ, Gilberto de Campos Fuzari Jr' \\ Maria Aparecida Zaghete ${ }^{2}$ and Ricardo Luiz Barros de Freitas ${ }^{3}$ \\ ${ }^{1}$ Faculdade de Engenharia, UNESP - Univ. Estadual Paulista - Campus de Iha Solteira, \\ Depto de Física e Química, Grupo de Polímeros, \\ ${ }^{2}$ Instituto de Química, Universidade Estadual Paulista - UNESP, \\ ${ }^{3}$ Faculdade de Engenharia, UNESP - Univ. Estadual Paulista - Campus de Iha Solteira, \\ Departamento de Engenharia Elétrica \\ Brazil
}

\section{Introduction}

Within the past 5 decades the use of ferroelectric composite made of ferroelectric ceramic immersed in polymer matrix has expanded significantly. One of the goals to embedding ceramic grains within a polymer matrix to form a $0-3$ composite film is to combine the better properties of each phase, such as high piezoelectric activity of the ceramic and the mechanical resistance, formability and flexibility of the polymer, also because the 0-3 composite is the easier and cheaper way to fabricate this alternative electro-active material.

Some desirable properties for composite materials are: high piezoelectric charge and voltage coefficients for passive piezoelectric devices; large piezoelectric charge coefficient and low relative dielectric constant for active devices. Furthermore, the poling process of the composite film should be effective, which impose the composite must be homogeneously fabricated, i.e., the composite film should have uniformly dispersed ceramic grain.

Piezoelectric devices have some specific advantages over electromagnetic such as suitability to be miniaturized; there is no need of magnetic shielding; it is more efficient at least in the lower power range. There is a very large range of applications of piezoelectric materials, either as sensing element or as actuators. One of the most recent interests on piezoelectric materials is energy harvesting, converting mechanical to electrical energy. The aim of this research area is to provide clean energy attending the needs of the world in the fight against pollution.

Conventional ferroelectric materials such as lead zirconate titanate (PZT) [JAFFE 1969, REN 2003, KLEE 2010], modified lead titanate [WANG 2000, CHU 2004, PONTES 2001] and ferroelectric polymers [LOVINGER 1983, KAWAI 1969, BAUER 2000] have been used in applications which use either piezo or pyroelectric properties. Concerned to the 
piezoelectric applications, they have been employed in a large range of transducers such as for hydrophone [LAU 2002, BOUMCHEDDA 2007], dynamic strain measurements [SOMAN 2011], medical ultrasound [ZHANG 2006, MURALT 2004] and non-destructive evaluation of structures [BROWN 1996, CIANG 2008, EDWARDS 2006].

On the pyroelectric applications, ferroelectric materials can be used as infrared detectors [SOSNIN 2000, HUANG 2002, GUGGILLA 2006] and X-ray intensity measurements [DE PAULA 2005, PONTES 2010, DE CARVALHO 1997]. Using the pyroelectric property of the sensing element, KUBE Electronics AG (Switzerland) has developed a flame detection and gas analysis device [www.kube.ch].

Ferroelectric ceramics have high piezo and pyroelectric properties but, for some applications, their poor mechanical properties and the mismatch of the acoustic impedance with water and human tissue restrict their usage. On the other hand, ferroelectric polymers have mechanical flexibility and formability but their piezo and pyroelectric activity are low. To overcome these problems composite materials made of ferroelectric ceramic and polymer have been investigated as an alternative material which combine the better properties of ceramic and polymer [FURUKAWA 1976, DIAS 1996, SAKAMOTO 2006, WONG 2006, KUMAR 2005, ESTEVAM 2011, FENG 2010].

According to Newnham and co-workers [NEWNHAM 1978] there are ten connectivity patterns in which a two phase composite system can be fabricated, ranging from unconnected 0-0 pattern to a 3-3 pattern in which both phases are three dimensionally selfconnected. The easier and cheaper composite to obtain is the 0-3 pattern, that means the ceramic grains are dispersed (unconnected) into a polymer matrix (self-connected three dimensionally). The main goal of embedding ferroelectric ceramic grains within a polymer matrix is to obtain a material which displays the combined better properties of each single phase. However it is very difficult to obtain a 0-3 composite with high ceramic content. There are basically two problems: high ceramic content will provide a mixed connectivity due to the percolation of the grains; high ceramic concentration means low flexibility of the composite material.

But these problems have not drawn the interest of researchers in using the 0-3 composite, on the contrary, it intensified the search for optimum results and many studies on the polarization of the composites have been conducted [FURUKAWA 1986, LAU 2007, PLOSS 2001, WONG 2002]. Still seeking a more effective polarization of the composite material, studies with the inclusion of a semiconductor phase were carried out [SA-GONG 1986, SAKAMOTO 2002, RENXIN 2006, PLOSS 2006, CHAU 2007]. These efforts were not in vain and 0-3 composites are being used as sensors and transducers, and is now a well-established alternative to conventional ferroelectric materials for many applications. New methods of preparing ferroelectric ceramics have also been studied and the latest is the hydrothermal method for obtaining ceramic powder [SHIMOMURA 1991, MORITA 2010]. The grain size and structure are also objects of study.

This work presents the preparation and characterization of PZT ceramic obtained by different methods. The influence of the synthesis method on the grain size and the morphology are also object of study. The fabrication and characterization of composite films with 0-3 connectivity, immersing nanoparticles of PZT into the non-polar poly(vinylidene fluoride) - PVDF as the polymer matrix were presented. For comparison there are some results obtained with composite samples made of ceramic particles 
recovered with a conducting polymer and also using the conducting polymer as a third phase. Moreover it presents the results obtained with the new material that includes a semiconductor phase, polyaniline - PAni as a sensing material and as a piezoelectric material for energy harvesting. In this sample the PZT grain was partially covered by PAni, which allowed better distribution of grains in the polymer matrix in comparison with the inclusion of the 3rd phase separately, avoiding a continuous electrical flux path which does not allow the polarization process of the composite sample. The use of this composite as sensor and power converter is an indicative that it is a good alternative for technological applications.

\section{Experimental}

\subsection{Ceramic}

The control of some parameters is important to achieve the desired properties in lead zirconate titanate (PZT) materials. These parameters include the absence of intermediate crystalline phases, a defined and fixed stoichiometry, as well as a homogeneous distribution of lead in the material. Lead zirconate titanate (PZT) is a very interesting ceramic that has good piezoelectric properties used to making ultrasonic transducers, filters and pyroelectric detectors [HAERTLING 1999]. This material can be prepared using different ways but the most important is using low temperature to obtain the crystalline phase. This condition promotes the homogeneous lead distribution and consequently occurs the formation of pure phase PZT. The presence of secondary phases reduces the dielectric and piezoelectric constants [ZAGHETE 1999, ZAGHETE 1992]. To minimize theses problems some chemicals processes has been proposed as the optional procedure. Methods such as sol-gel [ISHIKAWA 1994], hydrothermal synthesis [PAN 2007, ABOTHU 1999] and Pechini's method [ZAGHETE 1992] can be used.

It is known that ceramic materials prepared from chemical solutions routes are transformed via a nucleation and growth process, often requiring high temperatures to surmount the large energy barriers of the nucleation and growth of the stable phase. Consequently, these energy barriers frequently determine the calcinations conditions and therefore the characteristics such as, particle size, morphology and degree of aggregation of the precursor powder. The most significant advance in this field, however, consists of the ability to control phase development at low calcinations temperatures to avoid lead evaporation.

The expected phase equilibrium (perovskite) may grow starting from a gel matrix under a nucleus along a certain crystallographic orientation. This type of heterogeneous nucleation eliminates the need for the system to exceed the activation energy required to form the nucleus, as in the case of systems with homogeneous nucleation. As a result, the perovskite phase may crystallize at lower temperatures.

The present study show the influence of synthesis method on size and morphologic distribution of particle and the amount of perovskits phase synthesized at different temperatures. The procedure of PZT synthesis, based on Pechini's method [ZAGHETE 1992] makes use of the capability that certain a-hydroxycarboxylic organic acids possess of forming polybasic acid chelates with several cations. When mixing with a polyhydroxylic alcohol and heating, the chelate transforms into a polymer, maintaining the cations homogeneously distributed. 
The organic part is eliminated at low temperatures forming reactive oxides with wellcontrolled stoichiometry. Pure PZT with composition $\mathrm{Pb}\left(\mathrm{Zr}_{0.48} \mathrm{Ti}_{0.52}\right) \mathrm{O}_{3}$ can be prepared from the metal-citrate complex polyesterified in ethylene glycol. Appropriate quantities of $\mathrm{Zr}, \mathrm{Ti}$ and $\mathrm{Pb}$ solutions were mixed and homogenized by stirring at $90^{\circ} \mathrm{C}$ for $3 \mathrm{~h}$. Next, the temperature was increased to $130-140^{\circ} \mathrm{C}$, yielding a high viscous polyester resin. The powder was calcined at 600,700 and $800^{\circ} \mathrm{C}$ for $2 \mathrm{~h}$ and ball milled for $2 \mathrm{~h}$ in isopropylic alcohol medium.

Recently, the hydrothermal synthesis has been widely used in the study of these materials for the production of particles with nanometric sizes, high purity and crystallinity, good stoichiometric control and good yield. There are few reports relating to the study on the PZT synthesized by the hydrothermal method in literature. In one of these works, PZT powder was obtained with cubic morphology and crystalline phase by hydrothermal synthesis [PAN 2007]. By controlling the variables process of the synthesis, it becomes possible to change the morphology, the particle size, as well as the hydrothermal synthesis assisted by microwave method that has the advantage of producing rapid heating, thereby promoting homogeneous nucleation of particles [MOREIRA 2009, RAO 1999].

Hydrothermal media provide an effective reaction environment for the synthesis of numerous ceramic materials because of the combined effects of solvent, temperature, and pressure on ionic reaction equilibrium. The conventional hydrothermal method has become an effective synthetic route in Materials science by dramatically increasing the control of the micro/nanometric morphology and orientation [LUO 2008]. In addition, this method is environmentally friendly and depends on the solubility of the chemical salts in water under temperature and pressure conditions.

The key factors in this method are the vapor pressure and solubility of the chemical salts in water [LENCKA 1995]. In contrast to the conventional hydrothermal method which requires a long time typically several days and high electric power (over thousand watts) [DUTTA 1994], microwave-assisted heating is a greener approach to synthesize materials within a shorter time typically several minutes to some few hours less than the duration of the conventional method and with lower energy consumption (hundreds of watts).

The desired PZT product can be synthesized using $\mathrm{Pb}\left(\mathrm{NO}_{3}\right)_{2}, \mathrm{ZrOCl}_{2} .8 \mathrm{H}_{2} \mathrm{O}, \mathrm{TiO}_{2}, \mathrm{KOH}$. At first, a suspension containing $\mathrm{ZrOC}_{2} .8 \mathrm{H}_{2} \mathrm{O}, \mathrm{Pb}\left(\mathrm{NO}_{3}\right)_{2}$ and $\mathrm{TiO}_{2}$ was prepared in aqueous medium. After that, $\mathrm{KOH}$ aqueous solution containing 3.31g of $\mathrm{KOH}\left(1.84 \mathrm{~mol}\right.$. $\left.\mathrm{L}^{-1}, \mathrm{pH}=14\right)$. was add to the precursor suspension and then kept at room temperature under stirring for approximately 20 minutes. It was further placed containing all the reagents in Teflon jars, sealed and taken to the microwave for the synthesis of PZT powder.

The synthesis temperature was $180^{\circ} \mathrm{C}$ and the lower time used to obtain PZT was 0.5 hour, under constant pressure of approximately 10 Bar. The PZT powders were synthesized using microwave-assisted hydrothermal digester (MARS CEM, USA). The precursor was further again loaded into a $90 \mathrm{~mL}$ Tefflon autoclave reaching $30 \%$ of its volume. The autoclave was sealed and placed into a microwave-assisted hydrothermal system using $2.45 \mathrm{GHz}$ microwave radiation with a maximum output power of $800 \mathrm{~W}$. Then the solid product was washed with distilled water until a neutral $\mathrm{pH}$ was obtained and was further dried at room temperature. 


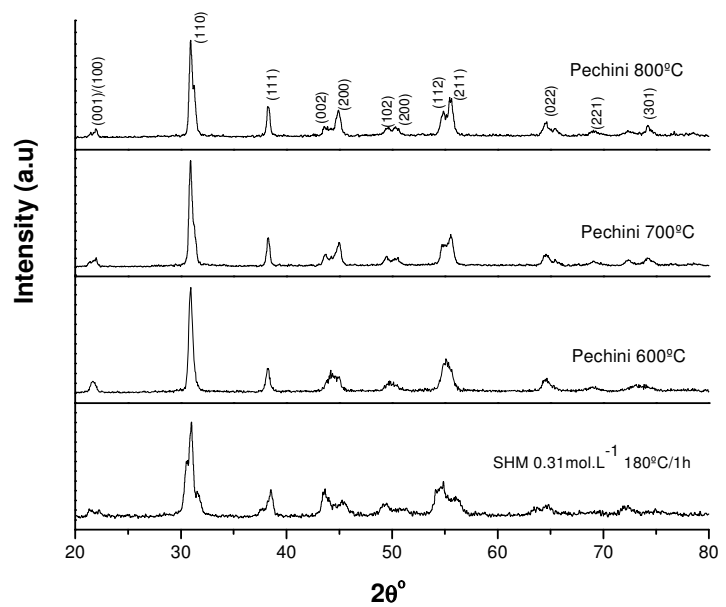

Fig. 1. X-ray diffraction patterns for PZT powders synthesized by Pechini method at different temperatures of calcination and hydrothermal synthesis assisted by microwaves.
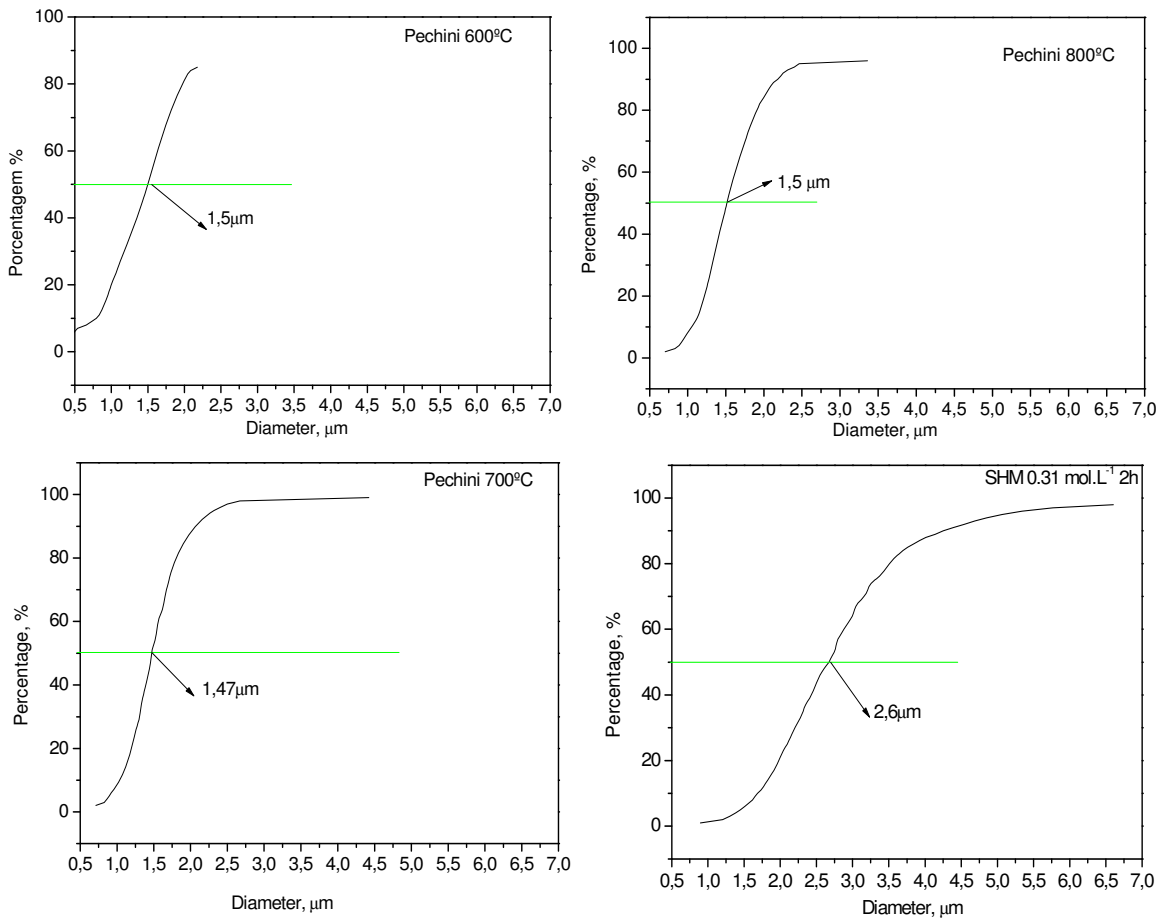

Fig. 2. Diagrams of particles size distribution of PZT synthesized by the Pechini's method calcimine at (a) $600^{\circ} \mathrm{C}$; (b) $700^{\circ} \mathrm{C}$; (c) $800^{\circ} \mathrm{C}$ and (d) synthesized by hydrothermal microwave method at $180^{\circ} \mathrm{C} / 1 \mathrm{~h}$. 


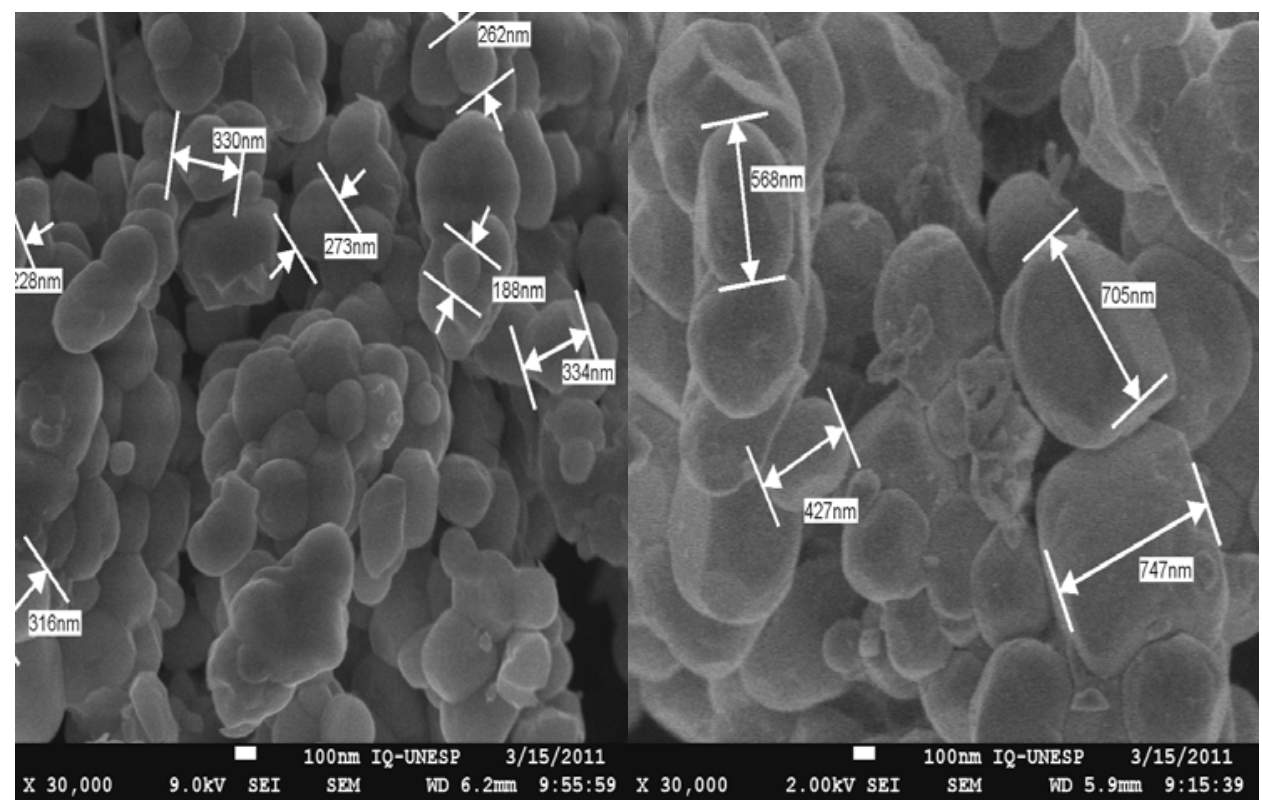

(A)

(B)

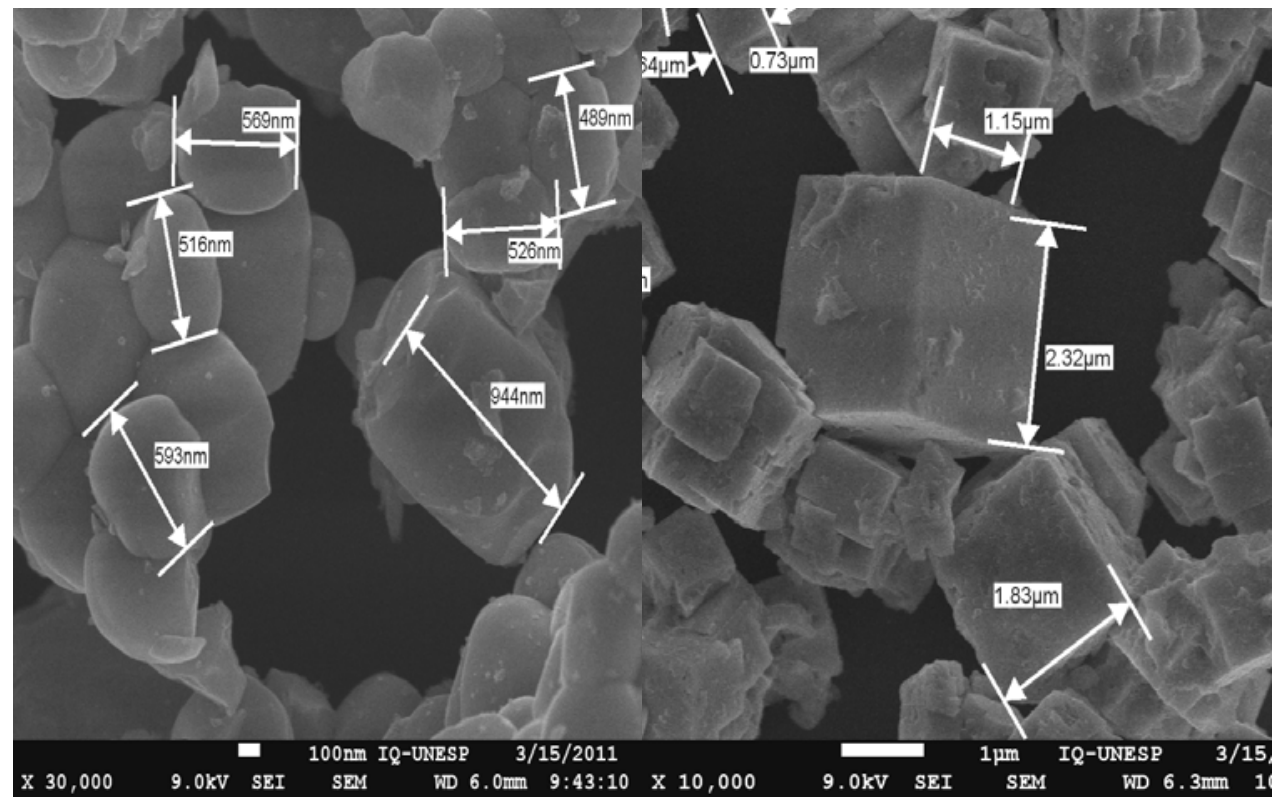

(C)

(D)

Fig. 3. FEG-SEM images of PZT nanostructures synthesized by Pechini's method: (a) $600{ }^{\circ} \mathrm{C} / 3 \mathrm{~h} ;(\mathrm{b}) 700^{\circ} \mathrm{C} / 3 \mathrm{~h},(\mathrm{c}) 800^{\circ} \mathrm{C} / 3 \mathrm{~h}$ and (d) synthesized by hydrothermal microwave method at $180^{\circ} \mathrm{C} / 1 \mathrm{~h}$. 
The obtained powders were characterized by X-ray powder diffraction using a Rigaku, DMax 2500PC with rotator anode at $50 \mathrm{kV}$ and $150 \mathrm{~mA}, \mathrm{Cu} \mathrm{Ka}$ radiation in the $2 \theta$ range from $20^{\circ}$ to $80^{\circ}$ with $0.02^{\circ} \mathrm{min}^{-1}$. A field emission gun scanning electron microscope (SEMFEG)-ZEISS SUPRA 35 microscope was used to analyze the shape and size of particles; energy dispersive X-ray microanalysis spectroscopy (EDS) was used for compositional determination. All measurements were taken at room temperature.

Today it is well known the effectiveness of the synthesis rote on the perovskits phase formation but it isn't well understood the influence of the particle size on the composite properties. Some of results obtained for PZT prepared by pechini's method and synthesis hydrothermal assisted by microwave were presented to show the different characteristic as function of the synthesis way.

The analysis of the crystal structure of the material indicated mixture of the tetragonal and rhombohedral phase that is characteristics of the morphotropic phase transition region (YU 2007) Figure 1. When prepared by the Pechini's method has been the formation of pure crystalline phase from $600^{\circ} \mathrm{C}$, the same result can be observed with hydrothermal treatment at $180^{\circ} \mathrm{C}$ for 1 hour. Also is possible to observe that the distribution of particle size and average particle size are directly affected by the temperature of thermal treatment as well as by the synthesis process, Figures 2 and 3. The purity of the composition was analyzed by EDS and found a homogeneous distribution of $\mathrm{Pb}, \mathrm{Ti}, \mathrm{Zr}$ on the surface of the entire sample as showed in Figure 4.

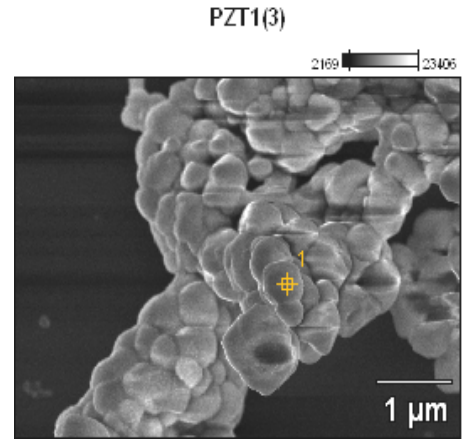

PZT4(1)

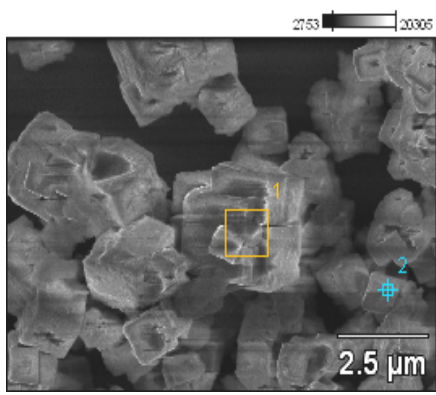

Full scale counts: 262

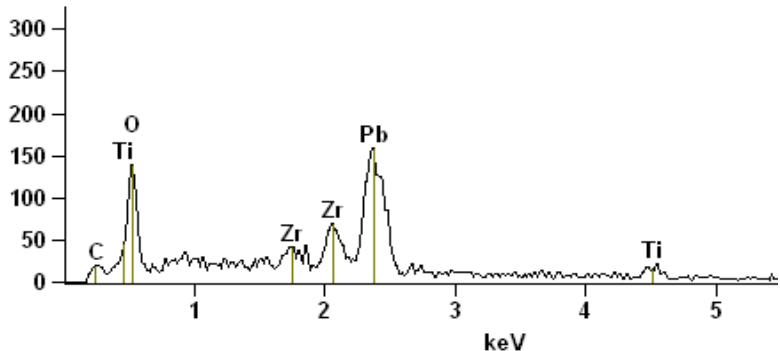

(a)

Full scale counts: 237

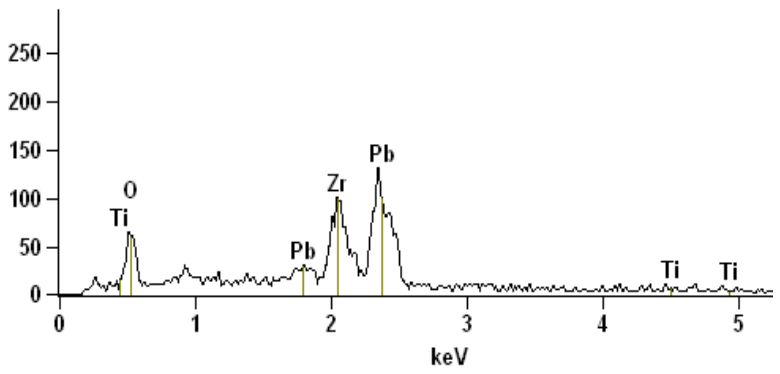

(b)
PZT1(3)_pt1

PZT4(1)_pt1

Fig. 4. Energy dispersive scanning, EDS, results of PZT prepared by Pechini's Method at (a) $700^{\circ} \mathrm{C} / 3 \mathrm{~h}$ and (b) synthesized by the hydrothermal microwave method. At $180^{\circ} \mathrm{C} / 1 \mathrm{~h}$. 


\subsection{Polymer matrix}

Poly(vinylidene fluoride) (PVDF) is a thermoplastic with excellent mechanical, optical and thermal properties, and showing resistance to attack of various chemicals [LOVINGER 1982]. Formed by repeated units of $\left(-\mathrm{H}_{2} \mathrm{C}_{-}-\mathrm{CF}_{2}-\right)_{\mathrm{n}}$, has a molecular weight around $105 \mathrm{~g} /$ mol. Depending on the means of acquiring or thermal history, PVDF can possess the degree of crystallinity from 45 to $60 \%$, melting temperature (Tm) in the range from 165 to $179^{\circ} \mathrm{C}$ and glass transition temperature $(\mathrm{Tg})$ of about $-34^{\circ} \mathrm{C}$. Its crystal structure is spherulitic (composed of lamellar crystalline radial). The range of relatively low melting temperature and some properties of the polymer described above ensure easy processing by melting and blending, which means great advantage in large scale production. The PVDF can also be processed by casting that may result in thin films.

Relative to the molecular structure, PVDF is a linear polymer that has permanent electric dipoles approximately perpendicular to the direction of their chains. These dipoles are formed by the electronegativity difference between atoms of hydrogen and fluorine. PVDF can be found in four distinct structural phases $a, \beta, \gamma$ and $\delta$. a phase is the most common, this being non-polar usually obtained by cooling molten. The $\beta$ phase (polar) is very attractive technical-scientific because of its piezoelectric and pyroelectric activity.

\subsection{Getting PZT grains coated with PAni}

The monomer aniline $\left(\mathrm{C}_{6} \mathrm{H}_{5} \mathrm{NH}_{2}\right)$ was purchased from Sigma-Aldrich and used in the synthesis after vacuum distillation. For the polymerization of aniline was employed oxidant ammonium persulfate from MERCK. To obtain the PZT particles partially coated with polyaniline, the PZT powder was incorporated into the solution of aniline and $1 \mathrm{M}$ cloridric acid under stirring at a temperature around $2^{\circ} \mathrm{C}$ for approximately $2 \mathrm{~h}$. The solution was filtered and washed with $0.1 \mathrm{M}$ hydrochloric acid and the product was dried in an oven at $50^{\circ} \mathrm{C}$ for $3 h$.

Figure 5 shows the FEG-SEM micrograph of (a) the PZT and (b) PAni-coated PZT particles. It can be seen the lack of smooth of the coated-particle surface.

\subsection{Composite}

The PVDF in the form of powder was mixed with pure PZT, the PZT particles coated with PAni and PAni and PZT placed separately. The mixtures were then placed between sheets of Kapton and pressed close to the melting temperature of PVDF. To find the optimum condition for preparation of the composite film the effect of pressing temperature, time and pressure to be taken by the mixtures were studied.The optimum conditions were found to be: temperature of $185^{\circ} \mathrm{C}$ for about 1 minute at a pressure of about $7.6 \mathrm{MPa}$. The thickness of the films was in the range from 100 to $420 \mu \mathrm{m}$ depending on the ceramic content. The composite films were obtained with different volume fractions of ceramic, which was calculated using the equation below [MARIN-FRANCH 2002]:

$$
m_{c}=\frac{m_{p} \rho_{c}}{\rho_{p}} \frac{\Phi_{c}}{1-\Phi_{c}}
$$

where $m$ is the mass and $\rho$ is the density. The subscript $c$ and $p$ are related to ceramic and polymer, respectively. $\Phi_{c}$ is the volume fraction of ceramic. Figure 6 shows FEG images of the composite sample. It can be seen the homogeneous distribution of the ceramic nanoparticles recovered with PAni. 


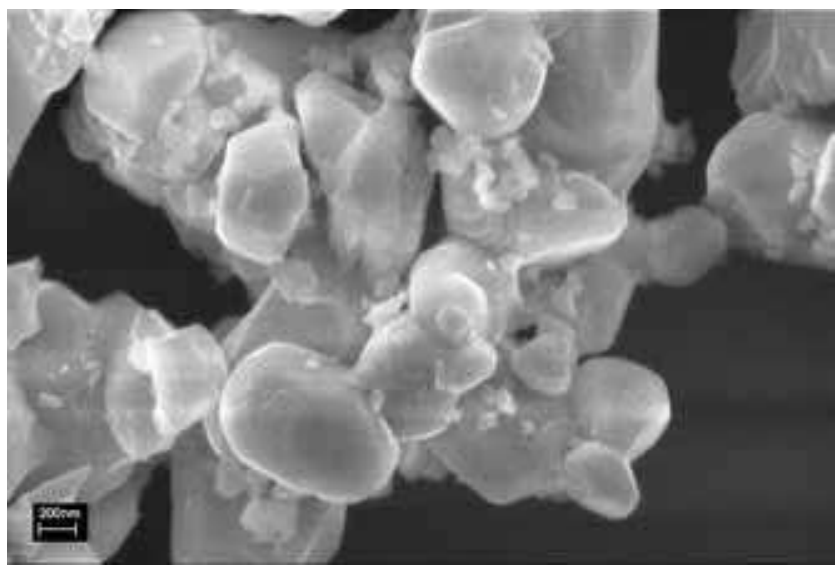

(a)

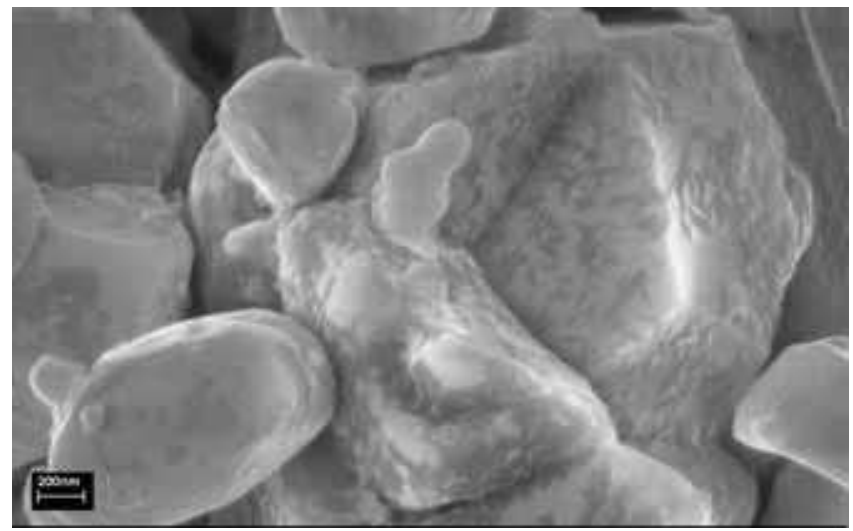

(b)

Fig. 5. FEG-SEM images: (a) PZT, (b) PZT recovered with PAni. 


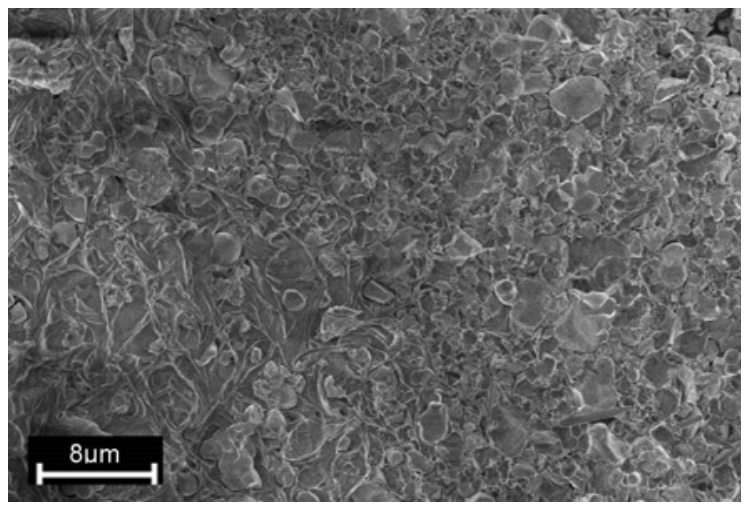

(a)

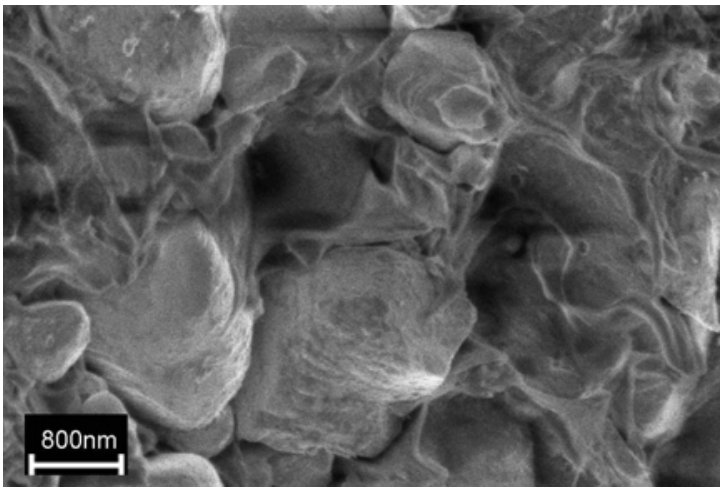

(b)

Fig. 6. FEG-SEM images (profile). (a) particle distribution into matrix e (b) particle recovered with PAni composite with $30 \mathrm{vol} \%$ of PZT-PAni.

The protonation degree of polyaniline can be controlled so that the conductivity of the composite, i. e, their permittivity can be changed and facilitate the polarization process [WEI 2007, WONG 2005, OR 2003, ZHOU 2005]. PAni can have its conductivity controlled by the $\mathrm{pH}$ [BLINOVA 2008], which means that in more acidic - $\mathrm{pH}$ below 4.0 - it begins to undergo the process of doping and its conductivity gradually increased with decreasing $\mathrm{pH}$.

\section{Characterization of the composite}

Aluminum electrodes with $1.0 \mathrm{~cm}$ of diameter were vacuum evaporated onto both sides of the sample for electrical contact. The composite films were poled with several electric field strengths and times in silicone oil bath with controlled temperature. A TREK high voltage power supply was used for the dc poling process. The dielectric data were taken using an impedance analyzer HP $4192 \mathrm{~A}$ in circular samples with $1.5 \mathrm{~cm}$ diameter.

An important aspect to note in materials is its electrical response when subjected to an alternating electric field. So it can be observed by measuring the impedance spectroscopy the behavior of dielectric constant versus frequency. Figure 7 shows the behavior of the real 
relative permittivity $\varepsilon^{\prime}$ and loss factor $\varepsilon^{\prime \prime}$ which have their highest values with the preparation of PZT-PAni at lower $\mathrm{pH}$ values, and in $\varepsilon^{\prime \prime}$ this increase is more significant. This is also an indication that the conductivity $\sigma$ of the material increases, since it is directly related to the permittivity $\varepsilon$ of the material by the relationship [POON 2004]:

$$
\sigma=\omega \varepsilon^{\prime \prime}-i \omega\left(\varepsilon^{\prime}-\varepsilon_{0}\right)
$$

where $\omega$ is the angular frequency of an external electric field applied and $\varepsilon_{0}$ is the electric permittivity in vacuum. In systems which contain grains covered with PAni doped partially or completely, $\varepsilon^{\prime}$ and especially $\varepsilon^{\prime \prime}$ reach high values at lower frequencies, and for these cases the magnitude of $\varepsilon^{\prime \prime}$ is bigger than $\varepsilon^{\prime}$, indicating high charge mobility, characteristics of the polymeric phase.

The piezoelectric activity of the composite films was studied by measuring the longitudinal piezoelectric coefficient $d_{33}$. The samples were poled in different poling conditions, changing parameters such as poling field, poling temperature and poling time. The best conditions of poling the sample were found as it can be seen in Figure 8 (a), (b) and (c).

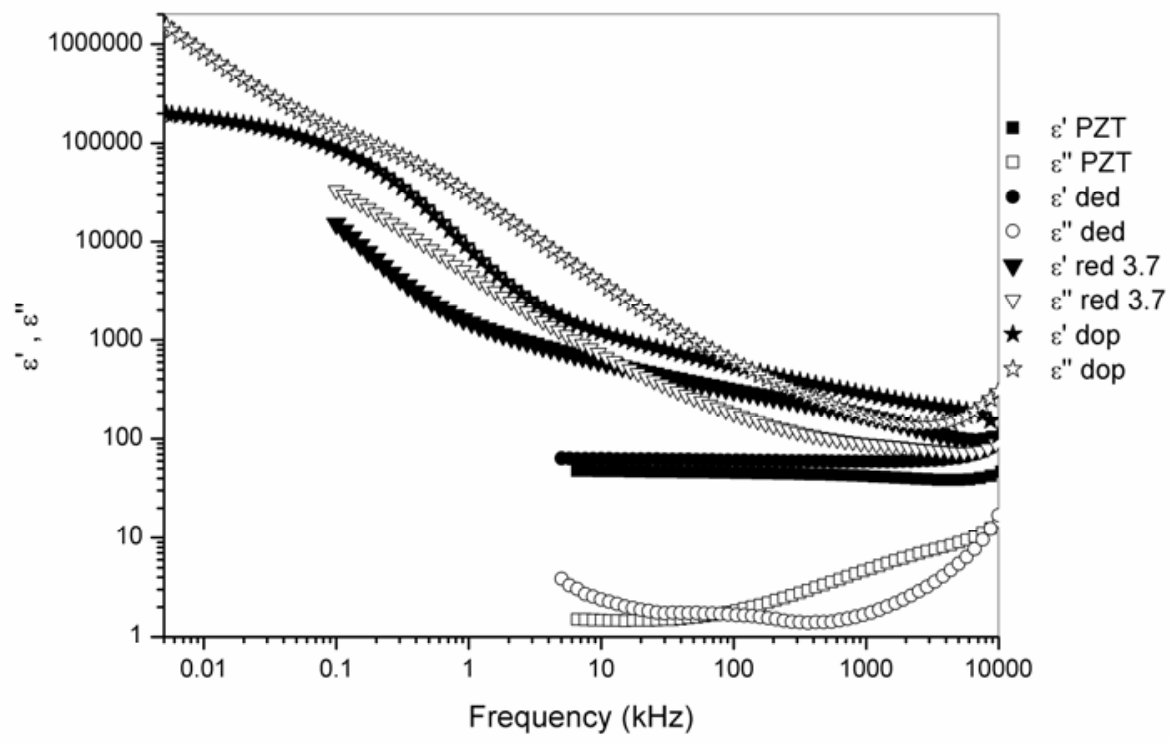

Fig. 7. Dielectric Constant as a function of frequency for PZT e PZT-PAni with different protonation degree. 


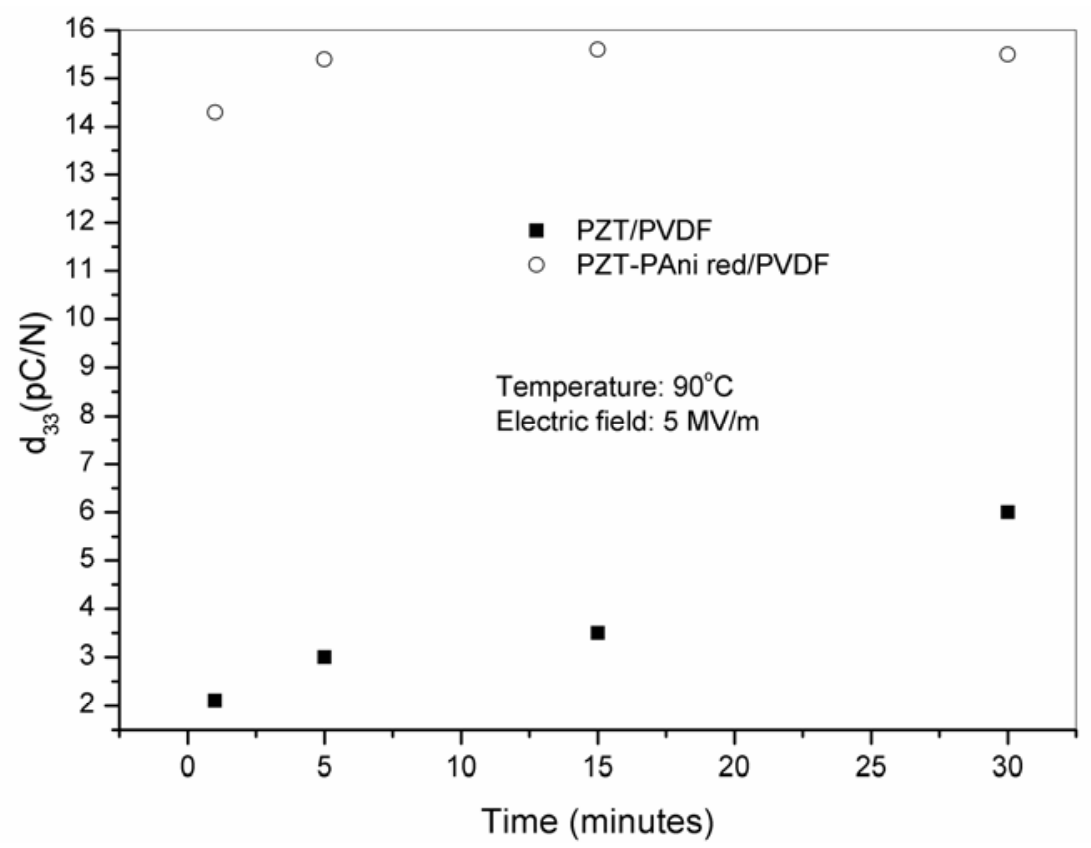

(a)

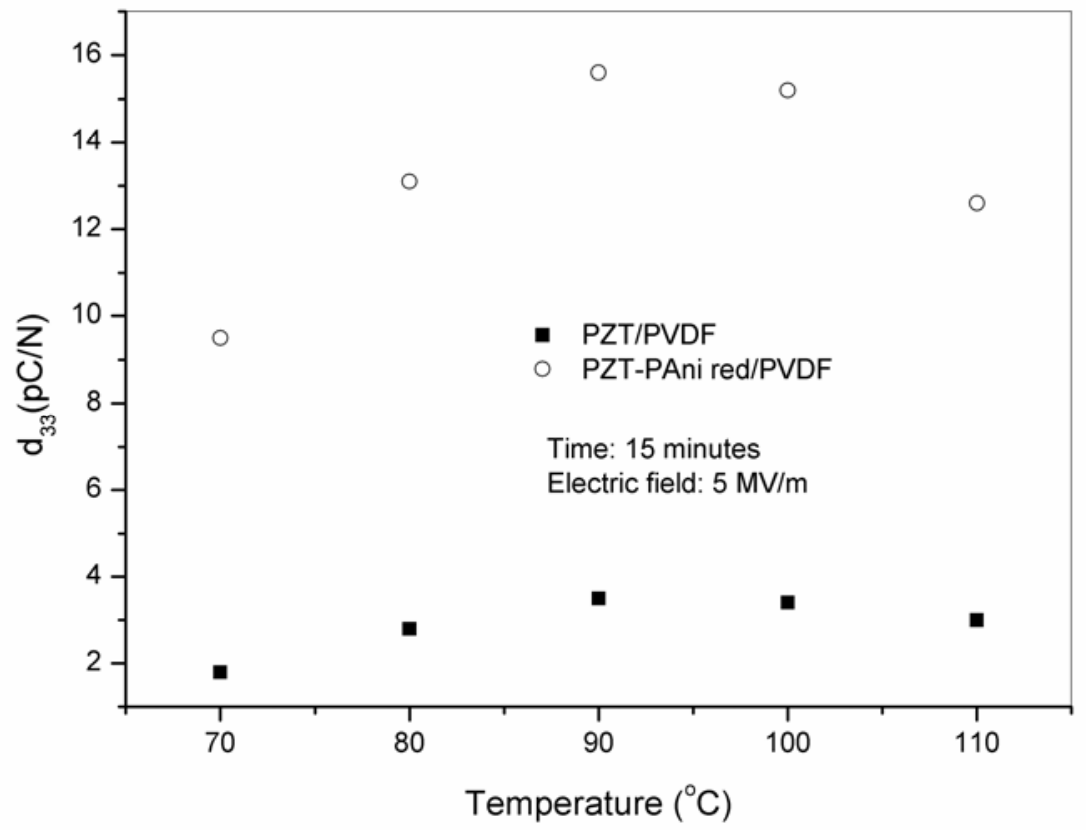

(b) 


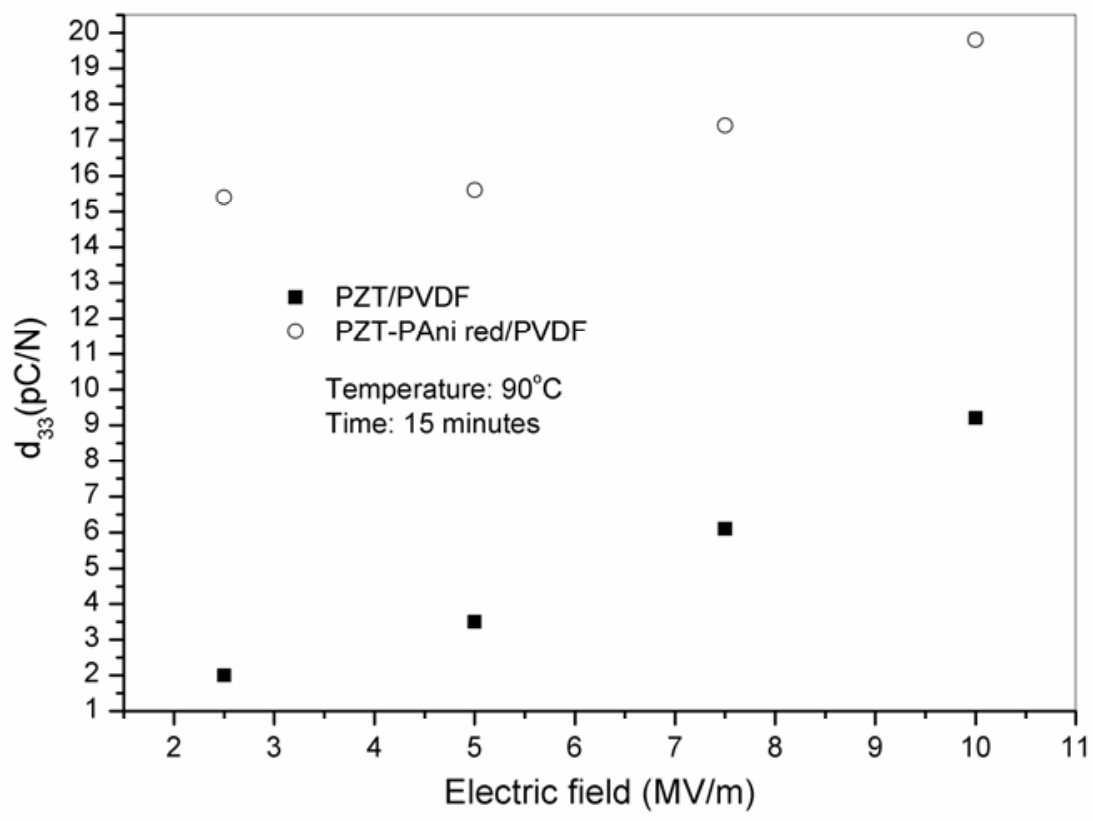

(c)

Fig. 8. Longitudinal piezoelectric coefficient $d_{33}$ :(a) As a function of poling time; (b) as a function of poling temperature and (c) as a function of applied electric field.

The longitudinal piezoelectric coefficient $d_{33}$ was measured with a Pennebaker Model 8000 Piezo d33 Tester, (American Piezo Ceramics Inc) coupled with a multimeter 34401A, (Hewlett Packard). To avoid problems related to non-uniformity of the composites, the measurement is made at least in 10 different points for each sample and the average of these points is taken as the coefficient $d_{33}$. Table 1 shows the values of $d_{33}$ piezo constant for some composite materials with respective volume fraction of ceramic. There is a clear indication that even for lower ceramic content, the piezoelectric activity of the PZT-PAni/PVDF composite, i.e., composite with ceramic particle covered with a conducting polymer phase is comparable with other composites with higher ceramic phase and much better than the PZT/PVC composite with the same ceramic volume fraction.

By means of thermally stimulated depolarization current (TSDC) is possible to obtain the pyroelectric coefficient $p(T)$. However it is necessary to clean up this curve, or leave it free from unwanted effects, such as the fluctuation of space charges injected during the polarization, since the interest is only the dipolar contribution, because it will remain even after heating the sample, if the provided temperature does not exceed the bias.

Figure 9 shows that for the first heating the depolarization current is greater than for the next heat, in which current tends to stabilize. This stabilized curve is the pyroelectric current, i.e., that due to dipolar relaxation. 


\begin{tabular}{ccc}
\hline Composites & $\begin{array}{c}\text { Volumetric } \\
\text { fraction of } \\
\text { ceramic }(\%)\end{array}$ & $d_{33}(\mathrm{pC} / \mathrm{N})$ \\
\hline PSTM/PEKK [PELAIZ-BARRANCO & 50 & 21 \\
2005] & 50 & 13 \\
PTCa/PEKK [PELAIZ-BARRANCO & & \\
2005] & 49 & 6 \\
PZT/PU with 1\% of graphite & 30 & 17 \\
(SAKAMOTO 2001) & 50 & 28 \\
PZT/PVC [LIU 2006] & 50 & $15-20^{*}$ \\
PZT/PVC [LIU 2006] & 30 & \\
PZT/PVDF with 10\% of PAni [RENXIN & 2006] &
\end{tabular}

Table 1. $D_{33}$ piezo constant for some composite materials.

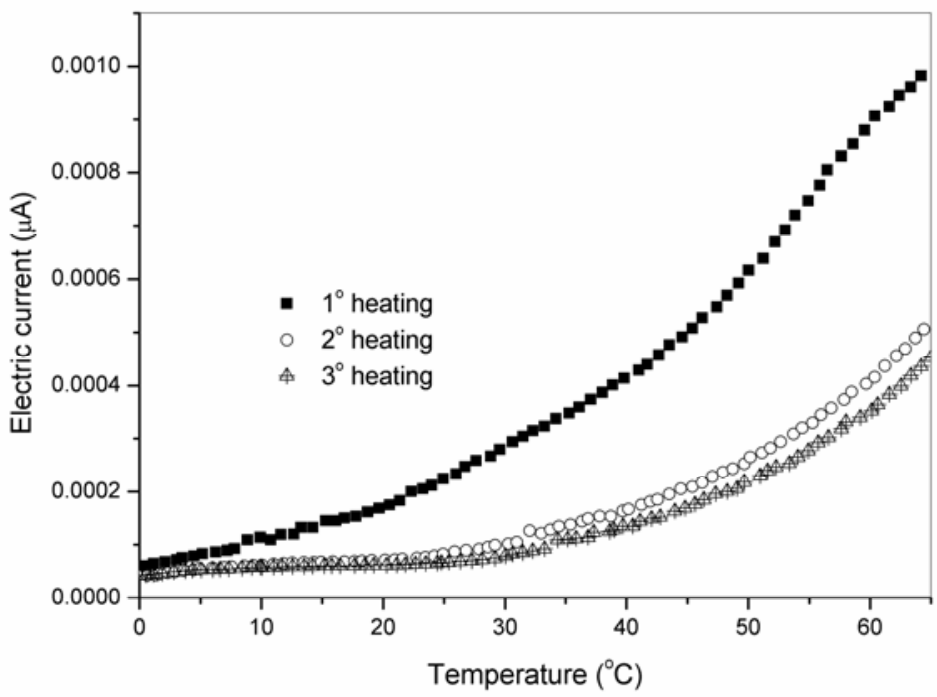

Fig. 9. Depolarization current for PZT-PAni/PVDF 30/70 vol\% with PAni redoped in $\mathrm{pH}=3.7$.

The pyroelectric coefficient $\mathrm{p}(\mathrm{T})$ can be obtained using the equation below:

$$
p(T)=\frac{d P}{d T}=\frac{d(Q / A)}{d T}=\frac{1}{A} \frac{d Q}{d T}=\frac{1}{A} \frac{d Q / d t}{d T / d t}=\frac{1}{A} \frac{I_{p}}{d T / d t}
$$

where $\mathrm{P}$ is the polarization, $\mathrm{A}$ the area of the electrode, Ip the pyroelectric current and $\mathrm{dT} / \mathrm{dt}$ the heating rate. Figure 10 shows the pyroelectric coefficient as a function of the temperature for different composites with 30 vol. \% of PZT. 


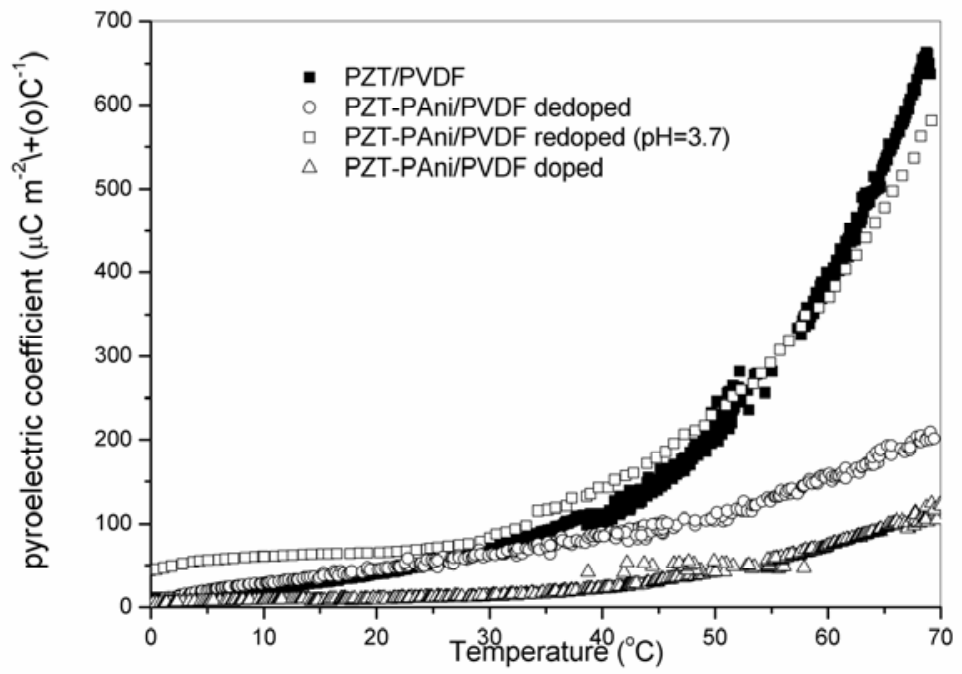

Fig. 10. Pyroelectric coefficient of composite with 30 vol.\% of PZT-PAni.

It can be observed low values of pyroelectric coefficient for composites PZT-PAni/PVDF fully doped $(\Delta)$. This effect is expected, since its polarization is hindered by the high conductivity of the films. For the composites PZT/PVDF and PZT-PAni/PVDF dedoped in the range of 0 to $40^{\circ} \mathrm{C}$ the behavior of the pyroelectric coefficients are similar, while the composite PZT-PAni/PVDF redoped ( $\mathrm{pH}$ 3.7) has larger values. At temperatures above $40^{\circ} \mathrm{C}$, the composite with PAni dedoped has little increase in pyroelectric coefficient with increasing temperature, while the composites PZT/PVDF and PZT-PAni/PVDF redoped having similar behavior, suffer a sharp increase. Table 2 shows the value of pyroelectric coefficient at room temperature for some composite materials. The composite with ceramic particle partially covered with PAni after suitable protonation degree display pyroelectric coefficient comparable with composite samples described in literature, which uses high ceramic volume fraction.

\begin{tabular}{ccc}
\hline Composite & $\begin{array}{c}\text { Volumetric fraction of } \\
\text { ceramic }(\%)\end{array}$ & $\mathrm{p}(\mathrm{T})\left(\mu \mathrm{C} \cdot \mathrm{m}^{-2} .{ }^{\circ} \mathrm{C}^{-1}\right)$ \\
\hline PZT/Epoxy [DAS-GUPTA 1999] & 40 & 40 \\
BaTiO3/rubber [DAS-GUPTA & 30 & 60 \\
1999] & 80 & 90 \\
TGS/PVDF [DAS-GUPTA 1999] & 62 & 130 \\
PT/PVDF [DAS-GUPTA 1999] & 50 & 10 \\
PZT/PVDF [DAS-GUPTA 1999] & 65 & 130 \\
PTCa/P(VDF-TrFE) [DAS-GUPTA & & 70 \\
1999] & 30 & \\
PZT-PAni/PVDF redoped in & & \\
pH=3.7
\end{tabular}

Table 2. Pyroelectric coefficient for some composite at room temperature 


\section{On the energy conversion}

For material to be used as a sensor, the relationship between output voltage and input power should be linear, i.e., the responsivity should remain constant. And regarding the magnitude of responsivity, it may indicate the quality of the sensor, i.e. the larger the magnitude, more input signal is being converted into output signal.

Four samples: two of PZT/PVDF 30/70 vol\%, one previously polarized with a electric field of $10 \mathrm{MV} / \mathrm{m}$ for 1 hour and another with a field of $5 \mathrm{MV} / \mathrm{m}$ for 15 minutes, a PZT/PVDF $50 / 50 \mathrm{vol} \%$ polarized with $10 \mathrm{MV} / \mathrm{m}$ for 1 hour, and one of PAni with 30/70 vol\% PZTPAni/PVDF redoped at $\mathrm{pH} 3.7$ and polarized with $5 \mathrm{MV} / \mathrm{m}$ for 15 minutes were compared. Figure 11 illustrates the behavior of the output voltage as a function of frequency and input power.

A close analysis of the results allows observing that the composite with polyaniline was superior in all respects in comparison to the other composites. Although the PZT/PVDF $50 / 50 \mathrm{vol} \%$ has close values of output voltage (Figure 11), the electric field and the time spent to polarize it were high. Furthermore, the ferroelectric ceramics content is higher. Without conducting phase in the composite the poling conditions have to be actually higher for the best properties of electroactivity. It can easily be observed when comparing the two composites PZT/PVDF 30/70 in volume. The composite polarized with higher electric field and spending more time showed higher output voltage. Yet comparing the composites with $30 \%$ load PZT or PZT-PAni, the latest presents better results.

In photopyroelectricity the upper face of the sample is painted with black ink to optimize the energy absorption. Since the sample works as a thermal transducer, absorbed modulated radiation increases the temperature of the sample and the heat is transformed into an electrical signal generated by the potential difference between the two faces of the sample. According to Mandelis and Zver [MANDELIS 1985] the photopyroelectric voltage $(\mathrm{V}(\omega))$ can be written, for the optically opaque and thermally thick pyroelectric sample, as:

$$
V(\omega)=\frac{A_{0}}{\omega} \exp \left[-\left(\frac{\omega}{2 \alpha_{s}}\right)^{1 / 2} L_{s}-i \varphi\right]
$$

where :

$$
A_{o}=\frac{p}{\varepsilon_{o} \kappa} \eta I_{o} F
$$

is the amplitude, $\eta$ is quantum efficiency, $\mathrm{I}_{0}$ is the light intensity, $\mathrm{F}$ is the thermal coefficient which depends on the thermal parameters of the sample, $\omega$ is the angular frequency of light modulation, $\alpha_{s}$ is the thermal diffusivity of the sample, $L_{s}$ the thickness and $\varphi$ is the phase of the photopyroelectric signal. In the amplitude $p$ is the pyroelectric coefficient, $\varepsilon_{0}$ the vacuum permittivity and $\kappa$ the relative permittivity.

The concept of energy harvesting must be related to capture the ambient energy and convert it into usable electrical energy without environment attack i.e., a clean electric energy. Although there are a number of sources of harvestable ambient energy, such as solar energy and energy from wind [SCHWEDE 2010, CHANG 2002], piezoelectric materials are very interesting due to their ability to convert applied strain energy into usable electric energy. Some countries are working hard on it and Israel, for example, using piezoelectric plates under the track, can obtain power enough to provide electricity to a medium house. 


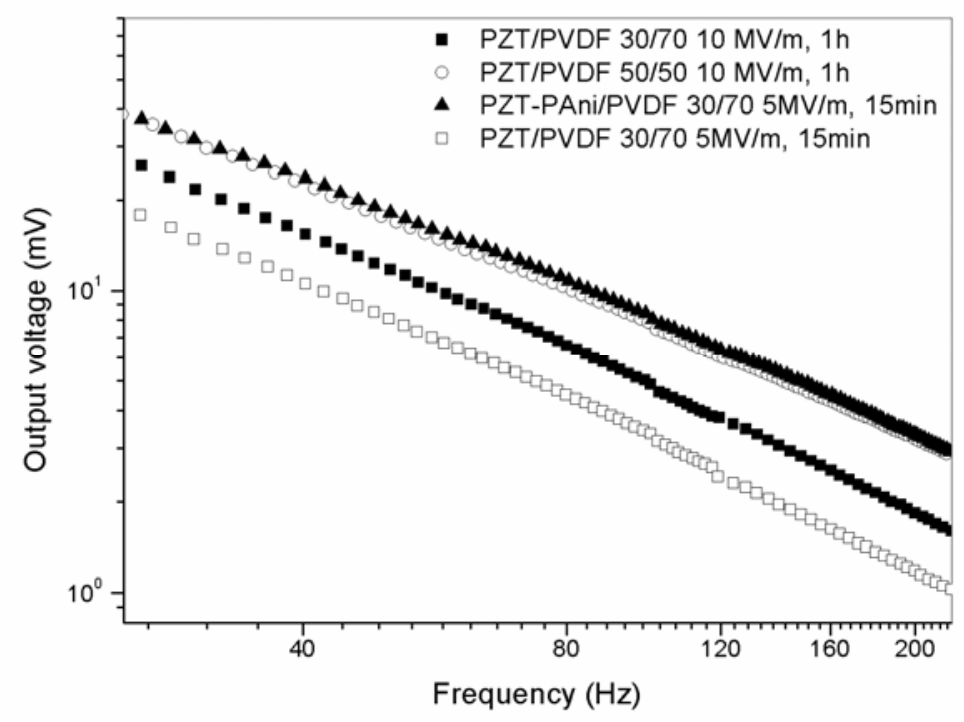

(a)

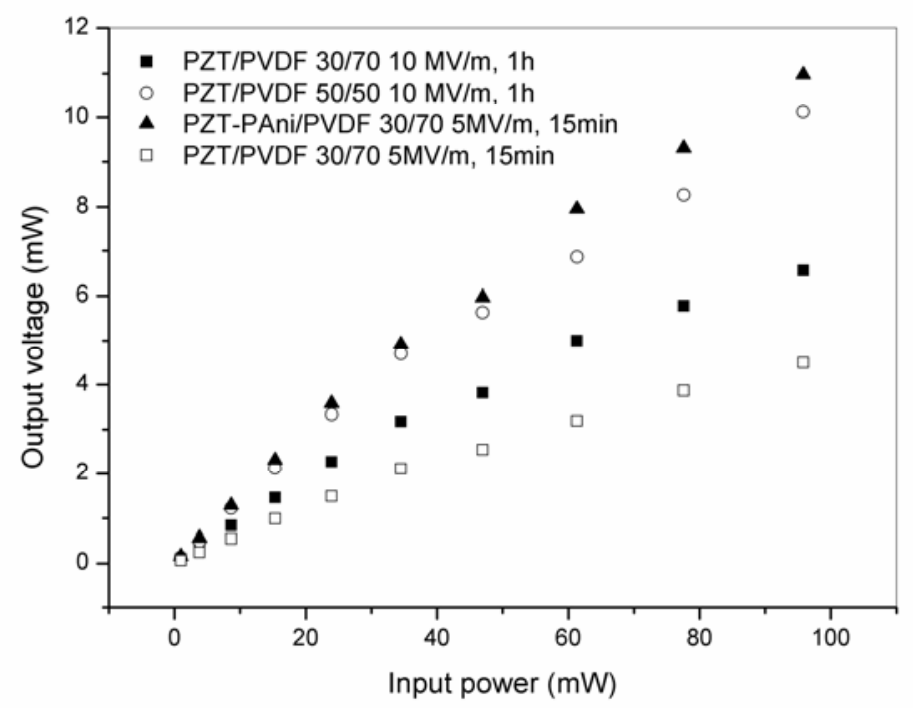

(b)

Fig. 11. (a) output voltage $\mathrm{x}$ frequency; (b) output voltage as a function of incident Power for different composites.

The energy recovery from the wasted energy used or not was a topic of discussion for a long time. Unused energy exists in various forms, such as vibration, water, wind, sun, heat, cold, human and vehicle movement, and shock waves. In today's world, there is a strong technological breakthrough in the way of life. More and more people are carrying portable 
electronic devices. These devices have and enable incredible power and versatility in communication and problem-solving. But as the technologies of portable computers and microcontrollers have grown tremendously, the battery energy and the storage technology did not follow them. New technology allows these portable devices become ever smaller, but the sizes of cells or batteries are still the same and the limited operating life is a great problem.

An alternative to the batteries and cells is the implementation of a method to obtain energy surrounding devices that could power supply them. Piezoelectric materials can be used to convert mechanical energy into electrical energy that can be used to power other devices. Energy harvesting using piezoelectric materials have attracted many attention of the researchers around the world. Many works have been published in this area [KOYAMA 2009, UMEDA 1997, SODANO 2004, ZHENG 2009, WANG 2010, ANTON 2007] and the focus is to find a material which gives power enough to allow its use commercially.

\begin{tabular}{|c|c|c|}
\hline Composite & $\begin{array}{c}\text { Thickness } \\
(\mu \mathrm{m})\end{array}$ & $\begin{array}{c}\text { Piezoelectric } \\
\text { Coefficient } \\
d_{33}(\mathrm{pC} / \mathrm{N})\end{array}$ \\
\hline $\mathrm{A}$ & 800 & 28 \\
\hline $\mathrm{B}$ & 600 & 28 \\
\hline $\mathrm{C}$ & 600 & 20 \\
\hline $\mathrm{D}$ & 700 & 10 \\
\hline
\end{tabular}

Table 3. Characteristic of the composite samples

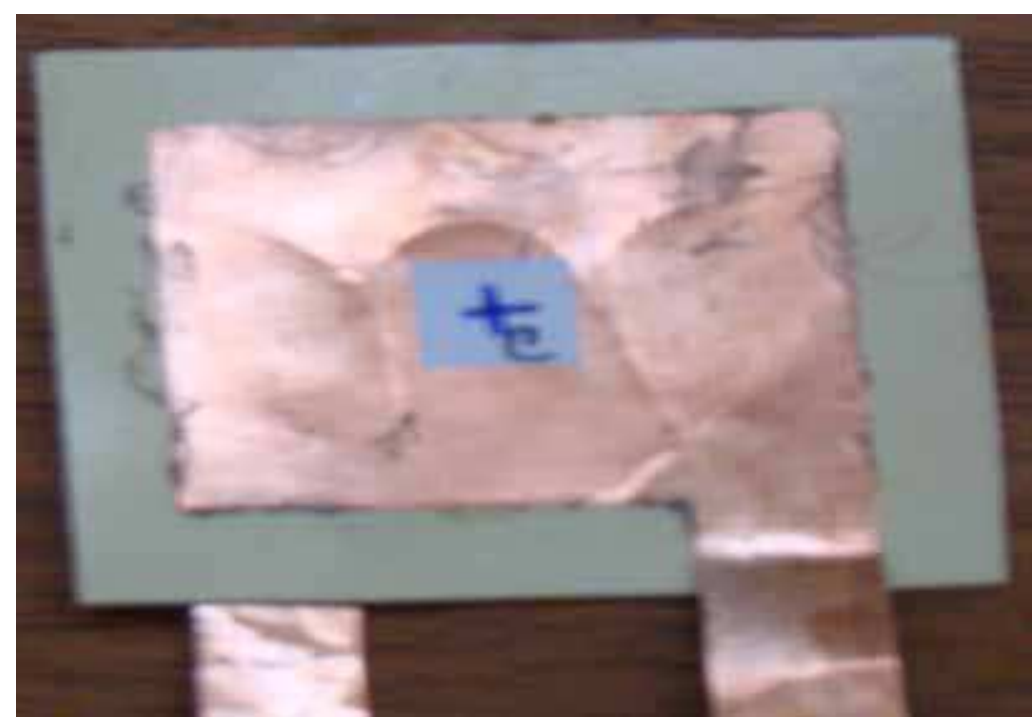

Fig. 12. Composite sample $50 \mathrm{vol} \%$ (grey) with cooper foil for electric contact.

The cantilever beam structure is one commum setup for energy harvesting. It uses PZT thin film to transforme the mechanical vibration into electrical energy. In the present work composite films were put under a track which will simulates car traffic or people movement. 
Within this context, four square composite samples with $4.5 \mathrm{~cm}^{2}$ were poled with suitable electric field and copper foil ( $1 \mathrm{~mm}$ thick) was glued for electrical contact as show in Figure 12. Table 3 shows the longitudinal $d_{33}$ piezoelectric coefficient for each one.

To evaluate the power generated by these samples, they were pressed by the blue car continuosly as shown in Figure 13. The weight and the frequency of the blue car which will impact the composite samples can be controlled and fixed during the experiment. The output voltage provided by the piezoelectric composite can be measured with an oscilloscope.

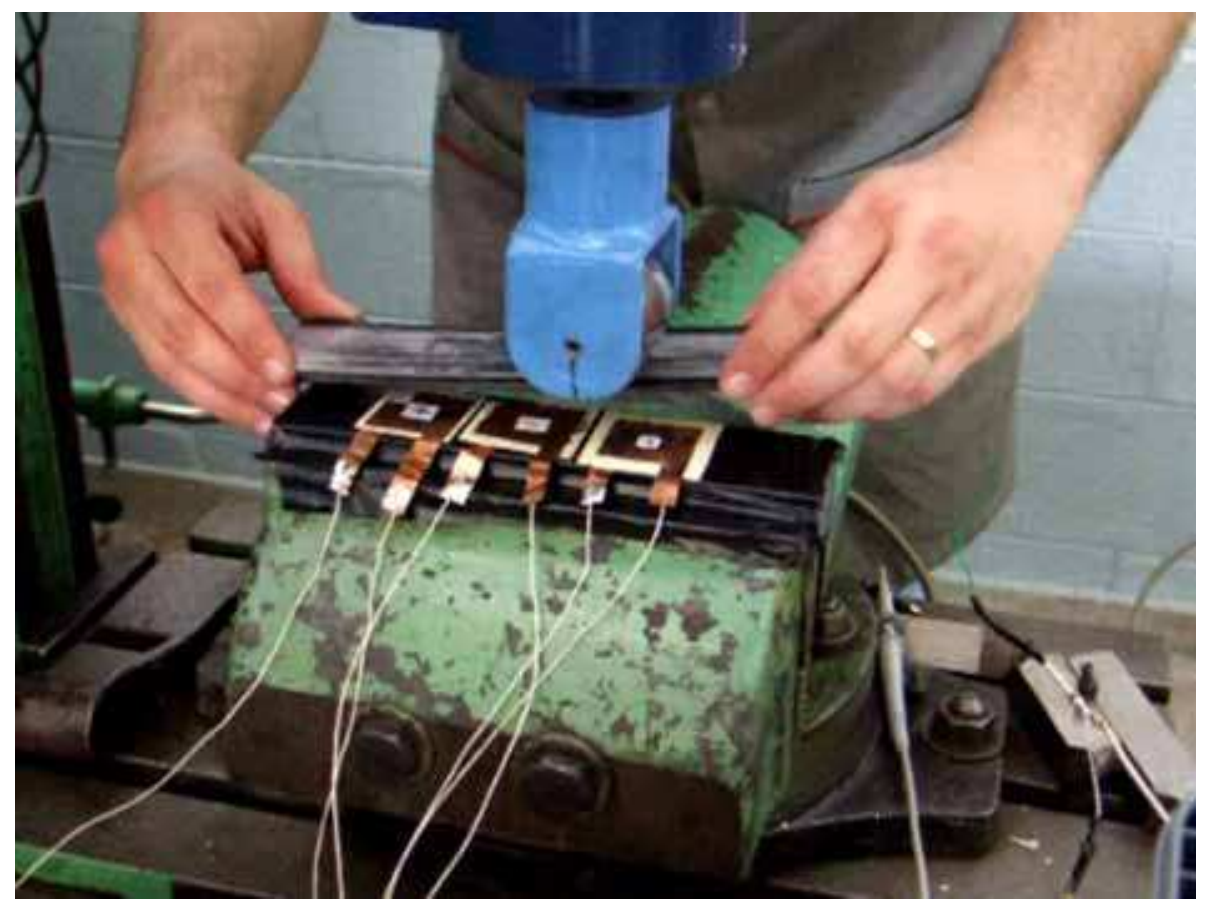

Fig. 13. System used to simulate the vehicle traffic or people walking.

A track is project and constructed with two parts. A bottom steel base with electrical tape on its top, fixed to a press device plane. A top made of aluminum with the bottom with duct tape, and attached to external screws that make this part of mobile resource, since the composite is between bottoms and top part of the track it receives the impact of the track above it. The composites were used as transducer individually, in series and in parallel. Then they were connected directly (open circuit) to acquire the waveforms from the digital oscilloscope. Further, the composites were connected in circuit (closed circuit) with the oscilloscope at the entrance acquiring waveforms again. Finally, voltages were measured at the capacitors for every minute during 10 minutes. Acquisition board was used to get the electrical signal provided by the composite. This board consists of a retifier circuit AC/DC and a output capacitor.

The experiments starts using a force of $200 \mathrm{kgf}$, to stroke the composites with a frequency of $3.0 \mathrm{~Hz}$, and a capacitor of $3300 \mu \mathrm{F}$. The open circuit (directly on the composites) and the 
closed circuit measurements for each composite, and combined composites in parallel (//) which are showed in Figure 14.

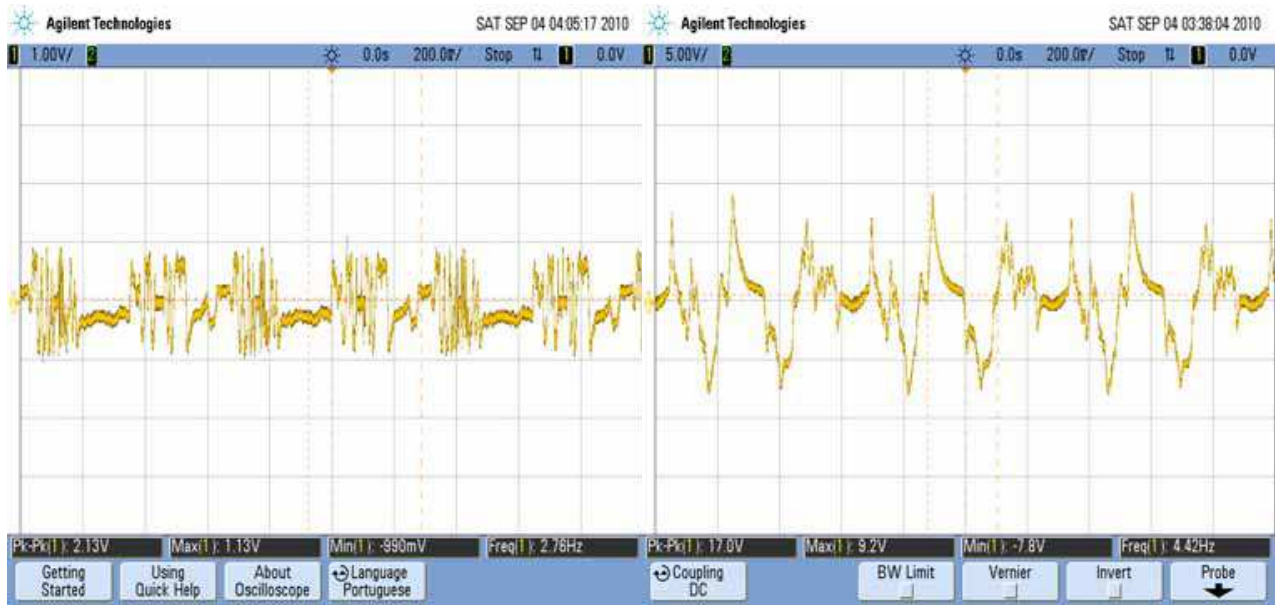

Fig. 14. Composites A// / / /C//D voltage measurement with open circuit (right)and closed circuit (left).

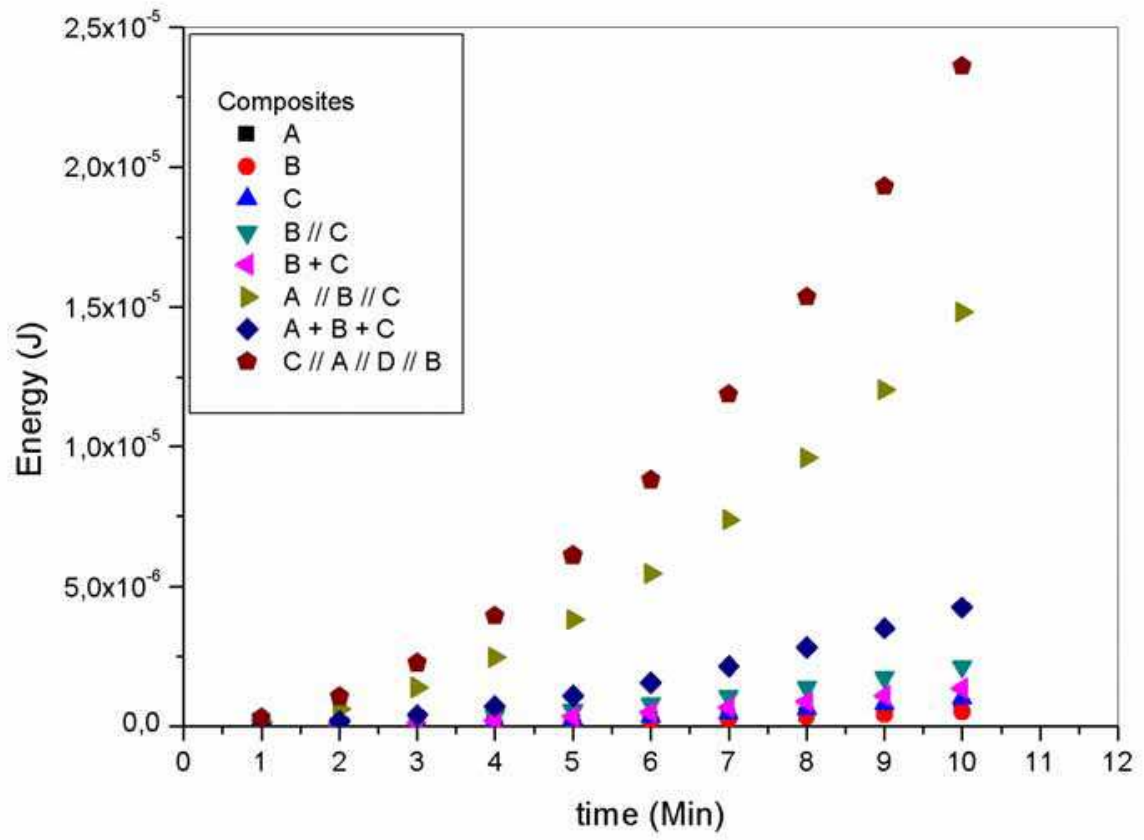

Fig. 15. Energy harvesting analysis. // means parallel connection; + represents a series connection. 
Experimental results show that an open circuit output voltage of $17.0 \mathrm{~V}_{\mathrm{pp}}$ are generated while in closed circuit the peak to peak voltage generated is $2.13 \mathrm{~V}$ because of the impedance of the capacitor.

Figure 15 shows the energy analysis of the experiments for different configurations of the composite films. It can be seen the increasing energy supplied when the composite films are connected in parallel. The useful energy, after $10 \mathrm{~min}$, by four composite films is about ten times higher than the energy generated by one composite film. The values of energy in Figure 15 were calculated from the measurement of the output voltage against time, using the following relation:

$$
U=\frac{1}{2} C V^{2}
$$

where $\mathrm{U}$ is the available energy and $\mathrm{V}$ is the voltage measured on the capacitor. The voltage was measured during the charge of the capacitor due to the deformation of the composite films by the applied stress.

\section{Conclusions}

Composite films made of PZT ceramic immersed in PVDF polymer matrix were obtained with 0-3 connectivity. The method of synthesis can provide different structure of the ceramic and also can provide ceramic particles with different size distribution which are important parameters for the electroactive properties of the sample. The inclusion of a semiconductor phase, separately or coating the ceramic particles improve the poling process of the composite, avoiding timing consuming and high applied electric field to polarize the ferroelectric ceramic particles immerse into the polymer matrix. The advantages of recovered particles is the better control of the homogeneity of the particle distribution avoiding percolation of conductive particles that may form a continuous path which not allow the poling process.

Using small amount of ceramic (30 vol\%) the composite was used as infrared detector, indicating the possibility of its use as intruder detector or fire alarm. Using the right protonation (doping) degree of the PAni, the composite display piezo and pyroelectric coefficients high as many composite materials with higher ceramic content even when poled with lower electric field and shorter poling time. The study of energy harvesting simulating people walking or vehicle traffic showed low power generated by each small composite sample $\left(4.5 \mathrm{~cm}^{2}\right.$ area) but the association of four samples enhanced the converted electrical energy from the energy wasted during vehicle traffic. These preliminary results show that the composite material deserves to be deeply studied as alternative material to obtain clean energy.

\section{Acknowledgment}

This work has financial support from the Brazilian Agencies: Fundação de Amparo à Pesquisa do Estado de São Paulo - FAPESP and Conselho Nacional de Desenvolvimento Científico e Tecnológico - CNPq through the Instituto Nacional de Ciência e Tecnologia de Materiais em Nanotecnologia - INCTMN. 


\section{References}

Abothu, I. R.; et. al. (1999) Processing of $\mathrm{Pb}(\mathrm{Zr} 0.52 \mathrm{Ti0}$.48)O3 (PZT) ceramics from microwave and conventional hydrothermal powders. Materials Research Bulletin, 34, (9), 14111419.

Anton, S. R. \& Sodano, H. A. (2007) A review of power harvesting using piezoelectric materials (2003 - 2006), Smart Mater. Struct., 16, R1 - R21.

Bauer, F. (2000) PVDF shock sensors: applications to polar materials and high explosives, IEEE Trans. Ultrason. Ferroelectr. Freq. Control, 47 (6), 1448 -1454.

Blinova, N. V., et. al. (2008) Control of polyaniline conductivity and contact angles by partial protonation, Polym. Int. 57, 66 - 69.

Boumchedda, K., Hamadi \& M., Fantozzi, G. (2007) Properties of a hydrophone produced with porous PZT ceramic, el European Ceram. Soc., 27, 4169 - 4171.

Brown L. F.\& Mason, J. L. (1996) Disposable PVDF Ultrasonic Transducers for Nondestructive Testing Applications, IEEE Trans. Ultrason. Ferroelectr. Freq. Control, $43(4), 560-567$.

Chang, L. (2002) Wind energy conversion systems, IEEE Canadian Review-Spring/Printemps, $12-16$.

Chau, K. H., Wong, Y. W., \& Shin, F. G. (2007) Enhancement of piezoelectric and pyroelectric properties of composite films using polymer electrolyte matrix, Appl. Phys. Lett., 91, 252910.

Chu, S-Y.\& Chen, T-Y. (2004) Fabrication of modified lead titanate piezoceramics with zero temperature coefficient and its application on SAW devices, IEEE Trans Ultras. Ferroelctr. Freq. Contr., 51 (6), 663 - 667.

Ciang, C. C., Lee, J-R.\& Bang, H-J. (2008) Structural health monitoring for a wind turbine system: a review of damage detection methods, Meas. Sci. Technol. 19, 122001.

Das-Gupta, D. K. (1999) Ferroelectric composite sensor materials, Mater. Eng., 10 (2), 97 125.

De Carvalho, A. A. \& Alter, A. J. (1997) Measurement of X-ray intensity in the medical diagnostic range by a ferroelectric detector, Ultrason. Ferroelectr. Freq. Control, 44 (6), $1198-1203$.

De Paula, M. H., et al. (2005) Microcontrolled pyroelectric instrument for measuring X-ray intensity in mammography, Med, Biol. Eng. Comput., 43, 751 - 755.

Dias, C. J.\& Das-Gupta, D. K. (1996) Inorganic ceramic/polymer ferroelectric composite electrets, IEEE Trans. Dielectr. Electr. Insul., 3 (5), 706 - 734.

Dutta, P.K., et. al. (1994) Hydrothermal Synthesis and Dielectric Properties of Tetragonal BaTiO3, Chem Mater., 6 (9):1542-1548.

Edwards, G., et. al. (2006) PMN-PT single-crystal transducer for non-destructive evaluation, Sensors and Actuators A, 132, $434-440$.

Estevam, G. P., De Melo, W. L. B. \& Sakamoto, W. K. (2011) Photopyroelectric response of PTCa/PEEK composite, Review of Scientific Instruments, 82, 023903.

Feng Y., et. al. (2010) A model for 0-3 piezoelectric composites with an interlayer, Polymer Composites, 1922 - 1927.

Furukawa, T., Fujino, K. \& Fukada, E. (1976) Electromechanical properties in the composites of epoxy resin and PZT ceramics, chn. el Appl. Phys. 15 (11), 2119 - 2129. 
Furukawa, T., Suzuki, K. \& Date, M. (1986) Switching process in composite systems of PZT ceramics and polymers, Ferroelectrics, 68, $33-44$.

Guggilla, P. et. al. (2006) Pyroelectric ceramics for infrared detection applications, Materials Letters, 60, 1937 - 1942.

Haertling, G. H. (1999) Ferroelectric ceramics: history and technology, eburnal of the American Ceramic Society, 82, (4), 797-818.

Huang, Z., et. al. (2002) Infrared optical properties of $\mathrm{PbTiO}_{3}$ ferroelectric thin films, J. Phys. D: Appl. Phys., 35, 246 - 248.

Ishikawa, K., et. al. (1994) Crystallization and growth process of lead titanate fine particles from alkoxide-prepared powders, .epn. el Appl. Phys. 33, 3495.

Jaffe, H., Piezoelectric applications of ferroelectrics, IEEE Trans. Electr. Devices, 16 (6), 544 554 (1969).

Kawai, H. (1969) The piezoelectricity of poly(vinylidene fluoride), con. cl Appl. Phys., 8, 975 976.

Klee, M. et. al. (2010) Ferroelectric and piezoelectric thin films and their applications for integrated capacitors, piezoelectric ultrasound transducers and piezoelectric switches, IOP Conf. Series: Mater. Sci. and Eng. 8, 012008.

Koyama, D. \& Nakamura, K. (2009) Array configurations for higher power generation in piezoelectric energy harvesting, IEEE International Ultrasonics Symposium Proceedings, 1973 - 1976.

Kumar N. \& Nath, R. (2005) Ferroelectric phase stability studies in potassium nitrate: Polyvinylidene fluoride composite films, JAppl. Phys., 97, 024105.

Lau, S. T., et. al. (2002) Piezoelectric composite hydrophone array, Sensors and Actuators A, $96,14-20$.

Lau, S. T., et. al. (2007) A poling study of lead zirconate titanate/polyurethane 0-3 composites, el Appl. Phys., 102, 044104.

Lencka, M.M. \& Riman, R. E. (1995) Thermodynamics of the Hydrothermal Synthesis of Calcium Titanate with Reference to Other Alkaline-Earth Titanates, Chem. Mater., 7: $18-25$.

Liu, X-F., et. al. (2006) Piezoelectric and dielectric properties of PZT/PVC and graphite doped with PZT/PVC composites, Mater. Sci. Eng. B, 127, 261 - 266.

Lovinger, A. (1982) Developments in Crystalline Polymers-1, D. C. Basset Ed., Applied Science Publishers, 195 - 273 London.

Lovinger, A. (1983) Ferroelectric Polymers, Science, 220, 1115 - 1121.

Luo, Z., et. al. (2008) Self-assembly of BaMoO4 single-crystalline nanosheets into microspheres, Materials Chemistry and Physics, 110, 17- 20.

Mandelis, A. \& Zver, M. M. (1985) Theory of photopyroelectric spectroscopy of solids, $C$ Appl. Phys., 57 (9), 4421 - 4430.

Marin-Franch, P., et. al. (2002) PTCa/PEKK piezo-composites for acoustic emission detection, Sensors and Actuators A, 99236 - 243.

Moreira, M. L., et. al. (2009) Synthesis of Fine Micro-sized BaZrO3 Powders Based on a Decaoctahedron Shape by the Microwave-Assisted Hydrothermal Method, Crystal Growth \& Design, 833-839. 
Morita, T. (2010) Piezoelectric Materials Synthesized by the Hydrothermal Method and Their Applications, Materials, 3, 5236 - 5245.

Muralt, P.\& Baborowski, J. (2004) Micromachined Ultrasonic Transducers and Acoustic Sensors Based on Piezoelectric Thin Films, eburnal of Electroceramics, 12, 101 108.

Newnham, R. E., Skinner, D. P. \& Cross, L. E. (1978) Connectivity and piezoelectricpyroelectric composites, Mat. Res. Bull, 13, 525 - 536.

Or, Y., et. al. (2003) Modeling of poling, piezoelectric, and pyroelectric properties of ferroelectric 0-3 composites, el Appl. Phys. 94 (5).

Pan, Q., et. al. (2007) Intense blue-light emission from hydrothermally synthesized lead zirconate titanate platelets. Materials Letters, 61, (4-5), 1210-1213.

Pelaiz-Barranco, A. \& Marin-Franch, P. (2005) Piezo- pyro, ferro-, and dielectric properties of ceramic/polymer composites obtained from two modifications of lead titanate, $C$ Appl. Phys., 97, $03411-034414$.

Ploss, B., \& Kopf, S. (2006) Improving the pyroelectric coefficient of ceramic/ polymer composite by doping the polymer matrix, Ferroelectrics, $338,145-151$.

Ploss, B., et. al. (2001) Poling study of PZT/P(VDF-TrFE) composites, Composites Science and Technology, 61, $957-962$.

Pontes, D. S. L., et. al. (2001) Microstructural, dielectric and ferroelectric properties of calcium-modified lead titanate thin films derived by chemical processes, cl European Ceram. Soc., 21, 1107 - 1114.

Pontes, W., et. al. (2010) PZT, for measuring energy fluence rate of X-ray used in superficial câncer therapy, Instr. Sci. Technol., 38, 210 - 219.

Poon, Y. M. \& Shin, F. G. (2004) A simple explicit formula for the effective dielectric constant of binary 0-3 composites, el Mater. Sci., 39, 1277 - 1281.

Rao, K. J., et. al. (1999) Synthesis of Inorganic Solids Using Microwaves, Chem. Mater., 11, 882-895.

Ren, T-L., et.al. (2003) Piezoelectric and ferroelectric films for microelectronic applications, Mater. Sci.and Eng. B99, 159 - 163.

Renxin X., et. al. (2006) Dielectric and piezoelectric properties of 0-3 PZT/PVDF composite doped with polyaniline, cburnal of Wuhan University of Technology - Mater. Sci. Ed., 21 (1), $84-87$.

Sa-Gong, et. al. (1986) Poling flexible piezoelectric composites, Ferroelectrics Letters, 5, 13' 142.

Sakamoto, W. K., De Souza, E. \& Das-Gupta, D. K. (2001) Electroactive properties of flexible piezoelectric composites, Materials Research, 4 (3), 201 - 204.

Sakamoto, W. K., et. al. (2006) PTCa/PEEK composite acoustic emission sensors, IEEE Trans. Dielectr. Electr. Insul., 13 (5), 1177 - 1182.

Sakamoto, W. K., Marin-Franch, P. \& Das-Gupta, D. K. (2002) Characterization and application of PZT/PU and graphite doped PZT/PU composite, Sensors and Actuators A, 100, 165 - 174.

Schwede, J. W., et. al. (2010) Photon-enhanced thermionic emisión for solar concentrador Systems, Nature Materials, 9, 762 - 767. 
Shimomura, K., et. al. (1991) Preparation of lead zirconate titanate thin film by hydrothermal method, cpn. el Appl. Phys., 30, 2174 - 2177.

Sodano, H. A., Park, G. \& Inman, D. J. (2004) Estimation of electric charge output for piezoelectric energy harvesting, Strain, 40, 49 - 58.

Soman J.\& O'Neal, C. B. (2011) Fabrication and Testing of a PZT Strain Sensor for Soil Applications, IEEE Sensors eburnal, 11 (1), 78 - 85.

Sosnin, A. (2000) Image infrared converters based on ferroelectric-semiconductor thin-layer systems, Semiconductor Physics, Quantum Electronics \& Optoelectronics, 3 (4), 489 495.

Umeda, M., Nakamura, K. \& Ueha, S. (1997) Energy storage characteristics of a piezogenerator using impact induced vibration, cpn. el Appl. Phys., 36, 3146 - 3151.

Wang, C.M.; et. al. (2000) Calcium modified lead titanate thin films for pyroelectric applications, ISAF 2000. Proceedings of the 12th IEEE International Symposium on Applications of Ferroelectrics - ISAF, vol. 2, 771 - 774.

Wang, D-A. \& Ko, H-H. (2010) Piezoelectric energy harvesting from flow-induced vibration, J Micromech. Microeng. 20, 025019.

Wei, N., et. al. (2007) Effect of electrical conductivity on the polarization behaviour and pyroelectric, piezoelectric property prediction of 0-3 ferroelectric composites, $C$ Phys. D: Appl. Phys., 40, 2716 - 2722.

Wong, C. K. \& Shin, F. G. (2006) Effect of electrical conductivity on poling and the dielectric, pyroelectric and piezoelectric properties of ferroelectric 0-3 composites, cI Mater. Sci., 41, 229 - 249.

Wong, C. K. \& Shin, F. G. (2005) Electrical conductivity enhanced dielectric and piezoelectric properties of ferroelectric 0-3 composites, C. Appl. Phys. 97, 064111.

Wong, C. K., Wong, Y. W. \& Shin, F. G. (2002) Effect of interfacial charge on polarization switching of lead zirconate titanate particles in lead zirconate titanate/polyurethane composites, J. Appl. Phys., 92 (7), 3974 3978.

Yu. N. Zakharov, A. V. Borodin, \& V. Z. Borodin (2007) Pyroelectric properties of PZT -type ferroelectric ceramics in the morphotropic phase-transition region, Bulletin of the Russian Academy of Sciences: Physics , 71, (5), 709-710.

Zaghete, M. A., et. al. (1999) The Effect of Isostructural Seeding on the Microstructure and Piezoelectric Properties of PZT Ceramics, Ceramics International, 25, .239 - 244.

Zaghete, M. A., et. al. (1992) Phases Characterization In PZT Obtained From Organic Solutions Of Citrates. eburnal of the American Ceramic Society, 75, 2088 2093.

Zhang, Q. Q., et. al. (2006) High frequency broadband PZT thick film ultrasonic transducer for medical imaging applications, Ultrasonics, 44 , e711 - e715.

Zheng B., Chang, C-J. \& Gea, H. C. (2009) Topology optimization of energy harvesting devices using piezoelectric materials, Struct. Multidisc. Optim., 38, 17 $-23$. 
Zhou, Y., et. al. (2005) Effects of polarization and permittivity gradients and other parameters on the anomalous vertical shift behavior of graded ferroelectric thin films, J. Appl. Phys., 98, 034105. 


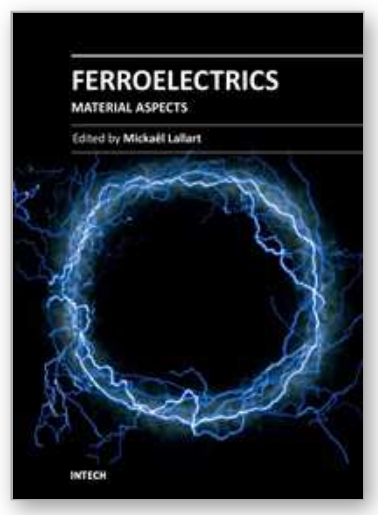

\author{
Ferroelectrics - Material Aspects \\ Edited by Dr. MickaÃ«l Lallart
}

ISBN 978-953-307-332-3

Hard cover, 518 pages

Publisher InTech

Published online 24, August, 2011

Published in print edition August, 2011

Ferroelectric materials have been and still are widely used in many applications, that have moved from sonar towards breakthrough technologies such as memories or optical devices. This book is a part of a four volume collection (covering material aspects, physical effects, characterization and modeling, and applications) and focuses on ways to obtain high-quality materials exhibiting large ferroelectric activity. The book covers the aspect of material synthesis and growth, doping and composites, lead-free devices, and thin film synthesis. The aim of this book is to provide an up-to-date review of recent scientific findings and recent advances in the field of ferroelectric materials, allowing a deep understanding of the material aspects of ferroelectricity.

\title{
How to reference
}

In order to correctly reference this scholarly work, feel free to copy and paste the following:

Walter Katsumi Sakamoto, Gilberto de Campos Fuzari Jr, Maria Aparecida Zaghete and Ricardo Luiz Barros de Freitas (2011). Lead Titanate-Based Nanocomposite: Fabrication, Characterization and Application and Energy Conversion Evaluation, Ferroelectrics - Material Aspects, Dr. Micka Ã«I Lallart (Ed.), ISBN: 978-953307-332-3, InTech, Available from: http://www.intechopen.com/books/ferroelectrics-material-aspects/leadtitanate-based-nanocomposite-fabrication-characterization-and-application-and-energy-conversion

\section{INTECH}

open science | open minds

\section{InTech Europe}

University Campus STeP Ri

Slavka Krautzeka 83/A

51000 Rijeka, Croatia

Phone: +385 (51) 770447

Fax: +385 (51) 686166

www.intechopen.com

\section{InTech China}

Unit 405, Office Block, Hotel Equatorial Shanghai

No.65, Yan An Road (West), Shanghai, 200040, China

中国上海市延安西路65号上海国际贵都大饭店办公楼405单元

Phone: +86-21-62489820

Fax: +86-21-62489821 
(C) 2011 The Author(s). Licensee IntechOpen. This chapter is distributed under the terms of the Creative Commons Attribution-NonCommercialShareAlike-3.0 License, which permits use, distribution and reproduction for non-commercial purposes, provided the original is properly cited and derivative works building on this content are distributed under the same license. 